\title{
Structure-Activity Relationships of Methylquercetin on Anti-migration and Anti-proliferation Activity in B16 Melanoma Cells
}

\author{
KOSEI YAMAUCHI ${ }^{1}$, TOHRU MITSUNAGA ${ }^{2}$, SYEDA H. AFROZE ${ }^{1}$ and MOHAMMAD N. UDDIN ${ }^{3,4,5}$ \\ ${ }^{1}$ Department of Medical Physiology, Texas A\&M Health Science Center College of Medicine, Temple, TX, U.S.A.; \\ ${ }^{2}$ United Graduate School of Agricultural Science, Gifu University, Gifu, Japan; \\ Departments of ${ }^{3}$ Obstetrics and Gynecology, ${ }^{4}$ Pediatrics and ${ }^{5}$ Internal Medicine, \\ Baylor Scott \& White Health/Texas A\&M Health Science Center College of Medicine, Temple, TX, U.S.A.
}

\begin{abstract}
Background: Melanoma is a malignant skin tumor and quercetin has been reported to inhibit metastasis. A quercetin glycoside and 7 methylquercetins were synthesized from rutin to investigate structure-activity relationships. Materials and Methods: We evaluated the anti-proliferative and anti-migration activity of quercetin glycoside and 7 methylquercetins in murine B16 melanoma cells by commercially available kits. We also examined the effect of these compounds on growth of human fibroblast cells to evaluate cytotoxicity. Results: 3-O-methylquercetin (2) exhibited 30, 38, 45\% migration activity at 25, 12.5, $6.25 \mu \mathrm{M}$ respectively. Furthermore, 3,4',7-O-trimethylquercetin (5) and 3,4'-O-dimethylquercetin (3) inhibited migration more potent than 2 with no cytotoxicity. 3-hydroxymethylquercetin and quercetin glycoside exhibited no anti-migration activity. Furthermore, the $\mathbf{3}$ and $\mathbf{4}$ inhibited melanoma proliferation with no cytotoxicity. Conclusion: The methoxyl group at the $C-3$ position plays an important role in inhibiting the migration of B16 melanoma cells.
\end{abstract}

Melanoma is a malignant skin tumor caused by ultraviolet (UV) damage to melanocytes, that are pigment-producing cells distributed on the surface of the skin, causing $75 \%$ of deaths related to skin cancer (1-3). Melanoma causes metastasis to the lymph nodes, bone, and lungs $(4,5)$. Numerous studies have reported anti-metastasis agents for

Correspondence to: Mohammad Nasir Uddin, $\mathrm{PhD}$, Department of Obstetrics \& Gynecology, Scott \& White Healthcare, Room 352 (Building 1), 2401 South 31st Street, Temple, TX 76508, U.S.A. Tel: +1 2547243624, Fax: +1 2547241046, e-mail: Mohammad. Uddin1@BSWHealth.org

Key Words: B16 melanoma cells, anti-migration, anti-proliferation, methylquercetin. melanoma. For example, CCT129254 and AT13148, Rho kinase inhibitors, dramatically reduce melanoma invasion (6). Galangin, a flavonoid isolated from the root of Alpinia officinarum, inhibits proliferation and metastasis of B16F10 melanoma through the suppression of Focal Adhesion Kinase (FAK), a cytoplasmic tyrosine kinase that is related to cellular processes such as proliferation, adhesion, and invasion (7).

Quercetin is a flavonoid present as a glycoside in various fruits and vegetables (8-10). Numerous studies have demonstrated that quercetin exhibits a variety of pharmacological effects, including antioxidant, antiinflammatory, and anti-cancer properties (11-13). Quercetin has been reported to inhibit migration and invasion of prostate cancer cells, and human hepatoma HepG2 cells $(14,15)$. It also inhibits migration and invasion of human oral cancer cells by reducing the protein levels of matrix metalloproteinase (MMP)-2, -7, -9 and -10, vascular endothelial growth factor (VEGF), and nuclear factor kappa-light-chain-enhancer of activated B cells (NF-kB) p65 (16). Furthermore, quercetin inhibits growth and metastasis in melanoma by suppressing the phosphorylation of c-Met downstream molecules including GRB2-associated-binding protein 1 (Gab1), FAK, and p21activated kinases relating to the metastasis (17-21). However, the structure-activity relationships using quercetin derivatives on anti-proliferation and anti-migration activity in B16 melanoma cells have not yet been elucidated. In our previous study, we evaluated the effect of two novel quercetin glycosides, 4'- $O$ - $\beta$-D-glucopyranosyl-quercetin-3-O- $\beta$-Dglucopyranosyl-( $(1 \rightarrow 4)-\beta$-D-glucopyranoside (9) and 4'-O- $\beta$ D-glucopyra-nosyl-(1 $\rightarrow 2)$ - $\beta$-D-glucopyranosyl-quercetin-3$O$ - $\beta$-D-glucopyranosyl-( $1 \rightarrow 4)-\beta$-D-glucopyranoside isolated from Helminthostachys zeylanica root extract on melanogenesis (23). Furthermore, 19 quercetin derivatives have also been synthesized from rutin similarly $(23,24)$. The anti-migration and anti-proliferation activities of the 7 
methylquercetin (2-8) and a quercetin glycoside (9) on B16 melanoma cells were investigated in this study (Figure 1). Furthermore, we investigated the effect of the quercetin derivatives on cell viability using human fibroblast cells to evaluate its application in humans.

\section{Materials and Methods}

Quercetin derivatives were synthesized using methods presented in our previous publication $(23,24)$. Murine melanoma B16-F0 cells (DS Pharma Biomedical, Osaka, Japan) were grown in Dulbecco's modified Eagle medium (DMEM) supplemented with $10 \%$ fetal bovine serum (FBS), 100,000 unit/L penicillin, and 100 $\mathrm{mg} / \mathrm{l}$ streptomycin. Human fibroblast cells (NB1RGB) were grown in Minimum Essential Medium (MEM) $\alpha$ supplemented with $10 \%$ FBS, 100,000 unit/L penicillin, and $100 \mathrm{mg} / \mathrm{l}$ streptomycin. Cells were cultured at $37^{\circ} \mathrm{C}$ in humidified atmosphere of $5 \% \mathrm{CO}_{2}$. The migration activity was performed using migration assay kits (CBA-100, Cell Biolabs, San Diego, CA, USA). Cell suspension containing $5.0 \times 10^{5}$ cells/well in $0.5 \%$ FBS DMEM was prepared. DMSO (control) and quercetin derivatives were added to the inside of each insert. A $500 \mu \mathrm{l}$ of DMEM including $10 \%$ FBS and quercetin derivative was added to the lower well of the migration plate and $300 \mu$ l of cell suspension solution was loaded into a cell culture inserts placed in 24 well plate. The cells were incubated with compounds at $37^{\circ} \mathrm{C}$ for $24 \mathrm{~h}$. Cells migrating to other sides of the inserts were stained, and the absorbance of extracted solutions was measured at $590 \mathrm{~nm}$ using a microplate reader.

Measurement of proliferation activity was performed according to a previously described method, using the microculture tetrazolium technique (MTT) (24). Following incubation with compounds for $72 \mathrm{~h}, 50 \mu \mathrm{l}$ of MTT reagent $(5 \mathrm{mg} / \mathrm{mL}$ of $3-[4,5-$ dimethyl-2-thiazolyl]-2,5-diphenyl-2H-tetrazolium bromide in PBS) was added to each well. The plates were incubated in a humidified atmosphere of $5 \% \mathrm{CO}_{2}$ at $37^{\circ} \mathrm{C}$ for $4 \mathrm{~h}$. After the medium was removed, $1.0 \mathrm{ml}$ of isopropyl alcohol (containing $0.04 \mathrm{~N} \mathrm{HCl}$ ) was added to each well, and a $150 \mu \mathrm{L}$ sample was withdrawn and transferred to a 96-well plate. Absorbance was measured at $590 \mathrm{~nm}$ by using a microplate reader.

B16 melanoma cells and human fibroblast cells were used to determine cytotoxicity of quercetin derivatives. Following incubation with compounds for $24 \mathrm{~h}, 50 \mu \mathrm{l}$ of MTT reagent was added to each well. The plates were incubated in a humidified atmosphere of $5 \% \mathrm{CO}_{2}$ at $37^{\circ} \mathrm{C}$ for $4 \mathrm{~h}$. After the medium was removed, $600 \mu \mathrm{l}$ of isopropyl alcohol (containing $0.04 \mathrm{~N} \mathrm{HCl}$ ) was added to each well, and a $150 \mu$ sample was withdrawn and transferred to a 96-well plate. Absorbance was measured at $590 \mathrm{~nm}$ by using a microplate reader.

Statistical method. Data from methylquercetin-treated in vitro experiments were compared to those from basal DMSO-treated controls using the Student's $t$-test with repeated measures design as methylquercetin dosages are varied within each experiment. Experiments were repeated 5 times to produce the replicates. Student's $t$-test was used to detect differences between the different methylquercetin dosages. All data were expressed as means \pm SD. A $p$-value of less than 0.05 was considered significant.
Table I. Migration of quercetin 1 and synthesized quercetin derivatives 2-9 in B16 melanoma cells.

\begin{tabular}{lccc}
\hline \multicolumn{3}{c}{ Migration activity (\%) } \\
\cline { 2 - 4 } & $25 \mu \mathrm{M}$ & $12.5 \mu \mathrm{M}$ & $6.25 \mu \mathrm{M}$ \\
\hline $\mathbf{1}$ & $43.5 \pm 9.7^{*}$ & $66.5 \pm 6.4^{*}$ & $75.1 \pm 1.8^{* *}$ \\
$\mathbf{2}$ & $30.4 \pm 1.8^{* *}$ & $37.8 \pm 2.6^{* *}$ & $45.0 \pm 1.8^{* *}$ \\
$\mathbf{3}$ & $27.5 \pm 2.4^{* *}$ & $32.9 \pm 1.4^{* *}$ & $59.1 \pm 2.8^{* *}$ \\
$\mathbf{4}$ & $44.5 \pm 8.1^{*}$ & $70.8 \pm 10.3$ & $99.1 \pm 0.4$ \\
$\mathbf{5}$ & $22.0 \pm 6.9^{* *}$ & $30.6 \pm 2.8^{* *}$ & $34.7 \pm 2.4^{* *}$ \\
$\mathbf{6}$ & $55.8 \pm 21.0$ & $96.3 \pm 9.6$ & $102.0 \pm 3.8$ \\
$\mathbf{7}$ & $71.3 . \pm 19.7$ & $95.1 \pm 11.6$ & $96.0 \pm 12.2$ \\
$\mathbf{8}$ & $100.7 \pm 4.3$ & $99.0 \pm 8.1$ & $130.9 \pm 18.5$ \\
$\mathbf{9}$ & $100.0 \pm 9.5$ & $104.5 \pm 52.4$ & $116.8 \pm 0.9$ \\
\hline
\end{tabular}

Data are expressed as means $\pm \mathrm{SD}(\mathrm{n}=2) .{ }^{*} p \leq 0.05$ and ${ }^{* *} p \leq 0.01$ compared to respective control values.

Table II. Cell viability of quercetin 1 and synthesized quercetin derivatives 2-9 in B16 melanoma cells. B16 melanoma cells were treated with the compounds using MEM $\alpha$ including $0.5 \%$ FBS.

\begin{tabular}{lccc}
\hline \multicolumn{3}{c}{ Cell viability $(\%)$} \\
\cline { 2 - 4 } & $25 \mu \mathrm{M}$ & $12.5 \mu \mathrm{M}$ & $6.25 \mu \mathrm{M}$ \\
\hline $\mathbf{1}$ & $92.7 \pm 8.1$ & $102.4 \pm 0.3$ & $82.9 \pm 1.1$ \\
$\mathbf{2}$ & $107.2 \pm 3.2$ & $106.9 \pm 0.8$ & $81.7 \pm 5.5$ \\
$\mathbf{3}$ & $111.1 \pm 1.4$ & $114.2 \pm 4.8^{*}$ & $106.8 \pm 3.0$ \\
$\mathbf{4}$ & $115.3 \pm 0.1$ & $115.3 \pm 1.4$ & $100.5 \pm 1.2$ \\
$\mathbf{5}$ & $94.5 \pm 0.7$ & $105.8 \pm 0.0$ & $99.6 \pm 5$. \\
$\mathbf{6}$ & $100.4 \pm 0.4$ & $86.7 \pm 2.8$ & $90.2 \pm 1.5$ \\
$\mathbf{7}$ & $86.5 . \pm 0.7$ & $85.1 \pm 4.1$ & $76.3 \pm 7.4$ \\
$\mathbf{8}$ & $92.9 \pm 3.5$ & $47.8 \pm 1.3^{* *}$ & $64.4 \pm 3.7^{*}$ \\
$\mathbf{9}$ & $93.7 \pm 1.9^{*}$ & $79.0 \pm 0.3$ & $78.4 \pm 0.4$ \\
\hline
\end{tabular}

Data are expressed as means $\pm \mathrm{SD}(\mathrm{n}=2) .{ }^{*} p \leq 0.05$ and ${ }^{* *} p \leq 0.01$ compared to respective control values.

\section{Results}

A quercetin glycoside and 7 methylquercetins were synthesized from rutin as a starting material. As shown in Table I, 3-O-methylquercetin (2) exhibited 30.4, 37.8, 45\% migration activity at $25,12.5,6.25 \mu \mathrm{M}$ respectively that is more potent than that of quercetin as the positive control. 3,7-O-dimethylquercetin (4) also inhibited migration to 44.5 , $70.8,99.1 \%$ at the same concentrations. Furthermore, 3,4',7$O$-trimethylquercetin (5) and 3,4'-O-dimethylquercetin (3) potently inhibited migration to $22.0,30.6,34.7 \%$ and 27.5 , $32.9,59.1 \%$ respectively at the same concentrations that is more potent than 2 and quercetin. 3-hydroxy methylquercetin and quercetin glycoside exhibited none or weak antimigration activity. 


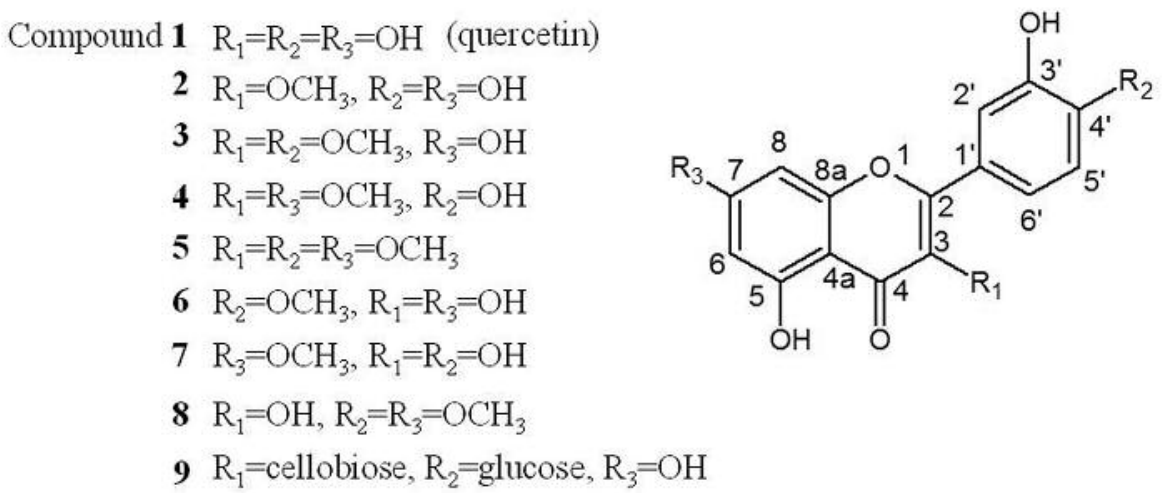

Figure 1. Structures of synthesized quercetin derivatives.

Cell viability of quercetin derivatives in B16 melanoma cells cultured with DMEM including 10\% FBS were described in the previous paper (24). Compounds $\mathbf{3}$ and $\mathbf{4}$ inhibited proliferation to $63.2,50.0,75.6 \%$ and $54.1,60.4,80.4 \%$ at 25 , $12.5,6.25 \mu \mathrm{M}$, respectively. In contrast, they exhibited no cytotoxicity in B16 melanoma cells cultured with DMEM containing 0.5\% FBS (Table II). Compounds $\mathbf{1 - 5}$ showing antimigration activity did not exhibit cytotoxicity. The proliferation activity of quercetin derivatives in human fibroblast cells are shown in Table III. Quercetin showed no effect on the proliferation in human fibroblast cells. Compound $\mathbf{2}$ slightly inhibited proliferation with no cytotoxicity. Compound $\mathbf{4}$ stimulated proliferation on $0.5 \%$ FBS MEM $\alpha$ to $161.3,153.3$, $130.2 \%$ at $25,12.5,6.25 \mu \mathrm{M}$, respectively, even though it did not increase on $10 \%$ FBS MEM $\alpha$. Compounds 5, 6, 7 and 8 also significantly increased cell numbers cultured with MEM $\alpha$ containing $0.5 \%$ FBS, without further increasing the number of cells in $10 \%$ FBS medium.

\section{Discussion}

Quercetin has been reported to inhibit migration and invasion of several types of cancer cells such as prostate cancer cells, human hepatoma HepG2 cells, human oral cancer cells, and melanoma (14-21). As seen in Table I, quercetin inhibits migration in a dose-dependent manner at 25-6.25 $\mu \mathrm{M}$ in B16 melanoma cells. In the present study, we evaluated the antimigration activity of quercetin derivatives that synthesized from rutin reported in our previous study. Compounds $\mathbf{6}, \mathbf{7}$, $\mathbf{8}$, and $\mathbf{9}$ did not inhibit or only gradually inhibited the migration. This anti-migratory activity is less potent compared to quercetin as a positive control. In contrast, 4 decreased the migration activity at the same level as quercetin, and 2, 3, and 5 that include 3-methoxyl group, inhibited the migration more potently than quercetin, suggesting that the 3-methoxyl group in methylquercetin is necessary to increase the anti-migration activity of quercetin.
Table III. Cell viability of quercetin 1 and synthesized quercetin derivatives 2-9 in human fibroblast cells. Fibroblast cells were treated with the compounds using MEM $\alpha$ including $10 \%$ or $0.5 \%$ FBS.

\begin{tabular}{|c|c|c|c|}
\hline & \multicolumn{3}{|c|}{ Cell viability $(\%)$} \\
\hline & $25 \mu \mathrm{M}$ & $12.5 \mu \mathrm{M}$ & $6.25 \mu \mathrm{M}$ \\
\hline \multicolumn{4}{|c|}{1} \\
\hline $10 \%$ FBS MEM $\alpha$ & $96.1 \pm 5.2$ & $97.7 \pm 1.4$ & $107.2 \pm 6.1$ \\
\hline $\begin{array}{l}0.5 \% \text { FBS MEM } \alpha \\
2\end{array}$ & $100.9 \pm 0.7$ & $94.9 \pm 0.3^{*}$ & $82.9 \pm 1.1 * *$ \\
\hline $10 \%$ FBS MEM $\alpha$ & $74.8 \pm 4.0 *$ & $74.8 \pm 0.0^{* *}$ & $75.3 \pm 0.0 * *$ \\
\hline $\begin{array}{l}0.5 \% \text { FBS MEM } \alpha \\
\mathbf{3}\end{array}$ & $119.9 \pm 1.7^{* *}$ & $104.5 \pm 1.0^{*}$ & $87.5 \pm 4.2$ \\
\hline $10 \%$ FBS MEM $\alpha$ & $83.0 \pm 3.6^{*}$ & $84.0 \pm 3.0 *$ & $92.9 \pm 8.7$ \\
\hline $\begin{array}{l}0.5 \% \text { FBS MEM } \alpha \\
4\end{array}$ & $114.6 \pm 2.5^{* *}$ & $105.8 \pm 4.7$ & $99.7 \pm 0.3$ \\
\hline $10 \%$ FBS MEM $\alpha$ & $78.3 \pm 7.5$ & $80.9 \pm 1.8^{* *}$ & $73,9 \pm 7.3$ \\
\hline $\begin{array}{l}0.5 \% \text { FBS MEM } \alpha \\
\mathbf{5}\end{array}$ & $161.3 \pm 1.4^{* *}$ & $153.3 \pm 1.3^{* *}$ & $130.2 \pm 1.4 * *$ \\
\hline $10 \%$ FBS MEM $\alpha$ & $101.3 \pm 4.8$ & $103.0 \pm 1.6$ & $103.1 \pm 0.2$ \\
\hline $\begin{array}{l}0.5 \% \text { FBS MEM } \alpha \\
6\end{array}$ & $134.1 \pm 0.8^{* *}$ & $129.1 \pm 1.0 * *$ & $120.8 \pm 0.8^{* *}$ \\
\hline $10 \%$ FBS MEM $\alpha$ & $100.4 \pm 1.2$ & $104.1 \pm 0.4$ & $103.4 \pm 1.0$ \\
\hline $\begin{array}{l}0.5 \% \text { FBS MEM } \alpha \\
7\end{array}$ & $135.9 \pm 0.6^{* *}$ & $107.5 \pm 0.9^{* *}$ & $101.1 \pm 2.1$ \\
\hline $10 \%$ FBS MEM $\alpha$ & $89.2 \pm 0.6$ & $100.9 \pm 1.0$ & $103.3 \pm 4.4$ \\
\hline $\begin{array}{l}0.5 \% \text { FBS MEM } \alpha \\
\mathbf{8}\end{array}$ & $138.0 \pm 3.5^{* *}$ & $132.2 \pm 1.5^{* *}$ & $119.0 \pm 2.0 * *$ \\
\hline $10 \%$ FBS MEM $\alpha$ & $110.8 \pm 0.6^{*}$ & $108.3 \pm 1.8^{*}$ & $113.1 \pm 1.4^{*}$ \\
\hline $\begin{array}{l}0.5 \% \text { FBS MEM } \alpha \\
\mathbf{9}\end{array}$ & $125.6 \pm 13.3$ & $122.5 \pm 2.8^{* *}$ & $101.7 \pm 5.9$ \\
\hline $10 \%$ FBS MEM $\alpha$ & $102.7 \pm 1.6$ & $106.7 \pm 4.4$ & $109.8 \pm 1.2 *$ \\
\hline $0.5 \%$ FBS MEM $\alpha$ & $96.6 \pm 3.1$ & $98.5 \pm 1.6$ & $91.9 \pm 9.1$ \\
\hline
\end{tabular}

Data are expressed as means $\pm \mathrm{SD}(\mathrm{n}=2) .{ }^{*} p \leq 0.05$ and $* * p \leq 0.01$ compared to respective control values.

The activity of 4, 7, 3-O-dimethylquercetin, was less than $\mathbf{2}$, which indicates that 7-methoxyl group did not increase the anti-migratory activity. While 3, 4', 7-O-trimethylquercetin 5 
and 3, 4'-O-dimethylquercetin 3 inhibited migration more than 2 that suggests that 4 '-methoxyl group stimulates the activity.

Cell viability in B16 melanoma cells of quercetin derivatives using DMEM including 10\% FBS was determined in our previous report (24). This study investigated the cytotoxicity using DMEM including 0.5\% FBS in B16 melanoma cells, which inhibited cell division and determined the proliferation activity using human fibroblast cells to estimate human application. Compounds $\mathbf{3}$ and $\mathbf{4}$ inhibited proliferation in B16 melanoma cells. However, they exhibited no effect in melanoma cells cultured with $0.5 \%$ FBS DMEM, suggesting the compounds inhibited proliferation without any cytotoxicity. Compounds $\mathbf{2}, \mathbf{3}$, and $\mathbf{5}$ elicited potent antimigration activity without affecting the cell viability in both $10 \%$ and $0.5 \%$ FBS DMEM. This data suggesting that the compounds directly inhibiting migration of B16 melanoma cells without reducing cell viability.

Table III illustrates quercetin derivatives $\mathbf{4 , 5}, \mathbf{7}$, and $\mathbf{8}$, all of which possess the 7-methoxyl group increased fibroblast cell numbers cultured with $0.5 \%$ FBS medium in a dose dependent manner, however they did not increase cell viability on $10 \% \mathrm{MEM} \alpha$. Alternatively, quercetin derivatives $\mathbf{1 , 2}, \mathbf{3}$, and 6 showed little to no effect in comparison with 4, 5, 7, and 8. The 7-methoxyl group of methlquercetin may play an important role in human fibroblasts proliferation in the absence of FBS. Fibroblast cells are known to play an important role in wound-healing and cosmetics. Dermal fibroblasts lose their proliferative capacity with aging (25). Dermal fibroblasts have been reported to decrease mitogenic responsiveness via decline of epidermal growth factor receptor in aging (26-28). Interestingly, 4 increased the number of human fibroblast in the absence of the growth factor; however, it inhibited proliferation in B16 melanoma cells. Compound 5 possesses 3 and 4-methoxyl groups that are involved in stimulation of anti-migration activity of B16 melanoma cells and 7-methoxyl group increasing human fibroblast proliferation. We could suggest that compound $\mathbf{5}$ exhibited both beneficial effects in the inhibition of migration, as well as an increase in fibroblast proliferation. These data strongly suggest that $\mathbf{5}$ and $\mathbf{4}$ might be used as a cosmetic tool and for wound healing purposes, as well an anticancer agent.

\section{Conclusion}

Quercetin and 8-series of quercetin derivatives were used to determine their anti-proliferation and anti-migration activity in B16 melanoma cells, in order to improve our understanding of their structure-activity relationships. Among the quercetin derivatives, 2, 3, and 5 potently inhibited migration more than quercetin, with no cytotoxicity observed. This result suggested that 3-methoxyl group in the methylquercetin plays an important role in the anti-migration activity and 4'-methoxyl group stimulates the activity. The discovery of the novel anti-migration, anti-proliferation and fibroblast growth promotion activity of methylquercetin supports further research into its potential anticancer applications, and into its possible uses in cosmetic products.

\section{Acknowledgements}

This research was supported by Japan Society for the Promotion of Science (JSPS) postdoctoral fellowship for research abroad (KY) and by The Discovery Foundation (MNU) and Grimes Foundation Endowment in Gynecologic Oncology (MNU).

\section{References}

1 Lawrence MS, Stojanov P, Polak P, Kryukov GV, Cibulskis K, Sivachenko A, Carter SL, Stewart C, Mermel CH, Roberts SA, Kiezsun A, Hammerman PS, McKenna A, Drier Y, Zou L, Ramos AH, Pugh TJ, Stransky N, Helman E, Kim J, Sougnez C, Abrogio L, Nickerson E, Shefler E, Cortés ML, Auclair D, Saksena G, Voet D, Noble M, DiCara D, Lin P, Lichtenstein L, Heiman DI, Fennell T, Imelinksi M, Hernandez B, Hodis E, Baca S, Dulak AM, Lohr J, Landau DA, Wu CJ, MelendezZajgla J, Hidalgo-Miranda A, Koren A, McCarroll SA, Mora J, Lee RS, Crompton B, Onofrio R, Parkin M, Winckler W, Ardlie K, Gabriel SB, Roberts CW, Biegel JA, Stegmaier K, Bass AJ, Garraway LA, Meyerson M, Golub TR, Gordenin DA, Sunyaev S, Lander ES and Getz G: Mutational heterogeneity in cancer and the search for new cancer-associated genes. Nature 499: 214-218, 2013.

2 Schadendorf D, Fisher DE, Garbe C, Gershenwald JE, Grob JJ, Halpern A, Herlyn M, Marchetti MA, McArthur G, Ribas A, Roesch A and Hauschild A: Melanoma. Nat Rev Dis Primers 4: 15003, 2015.

3 Schadendorf D and Hauschild A: Melanoma in 2013: Melanoma - the run of success continues. Nat Rev Clin Oncol 11: 75-76, 2014.

4 De Angelis R, Sant M, Coleman MP, Francisi S, Baili P, Pierannunzio D, Trama A, Visser O, Brenner H, Ardanaz E, Bielska-Lasota M, Engholm G, Nennecke A, Siesling S, Berrino F, Capocaccia R; EUROCARE-5 Working Group: Cancer survival in Europe 1999-2007 by country and age: Results of EUROCARE5 - a population-based study. Lancet Oncol 15: 23-34, 2014.

5 Livingstone E, Windemuth-Kieselbach C, Eigentler TK, Rompel R, Trefzer U, Nashan D, Rotterdam S, Ugurel S and Schadendorf D: A first prospective population-based analysis investigating the actual practice of melanoma diagnosis, treatment and follow-up. Eur J Cancer 47: 1977-1989, 2011.

6 Sadok A, McCarthy A, Caldwell J, Collins I, Garrett MD, Yeo M, Hooper S, Sahai E, Kuemper S, Mardakheh FK and Marshall CJ: Rho Kinase inhibitors block Melanoma cell migration and inhibit Metastasis. Cancer Res 75: 2272-2284, 2015.

7 Zhang W, Tang B, Huang Q and Hua Z: Galangin inhibits tumor growth and metastasis of B16F10 melanoma. J Cell Biochem 114: 152-161, 2012.

8 Hertog MGL, Hollman PCH and Katan MB: Content of potentially anticarcinogenic flavonoids of 28 vegetables and 9 fruits commonly consumed in the Netherlands. J Agric Food Chem 40: 2379-2383, 1992. 
9 Hollman PCH and Katan MB: Dietary Flavonoids: Intake, health effects and Bioavailability. Food Chem Toxicol 37: 937-942, 1999.

10 Manach C, Scalbert A, Morand C, Rémésy C and Jiménez L: Polyphenols: food sources and bioavailability. J Nutr 79: 727747, 2004

11 Gibellini L, Pinti M, Nasi M, De Biasi S, Bertoncelli L and Cossarizza A: Interfering with ROS metabolism in cancer cells: The potential role of Quercetin. Cancers 2: 1288-1311, 2010.

12 Chen Q-X and Kubo I: Kinetics of mushroom Tyrosinase inhibition by Quercetin. J Agric Food Chem 50: 4108-4112, 2002.

13 Jackson JK, Higo T, Hunter WL and Burt HM: The antioxidants curcumin and quercetin inhibit inflammatory processes associated with arthritis. Inflamm Res 55: 168-175, 2006.

14 Senthilkumar K, Arunkumar R, Elumalai P, Sharmila G, Gunadharini DN, Banudevi S, Krishnamoorthy G, Benson CS and Arunakaran J: Quercetin inhibits invasion, migration and signalling molecules involved in cell survival and proliferation of prostate cancer cell line (PC-3). Cell Biochem and Funct 29: 87-95, 2011

15 Lee W-J, Wu L-F, Chen W-K, Wang C-J and Tseng T-H: Inhibitory effect of luteolin on hepatocyte growth factor/scatter factor-induced HepG2 cell invasion involving both MAPK/ERKs and PI3K-Akt pathways. Chem Biol Interact 160: 123-133, 2006.

16 Lai W, Hsu S, Cheuh F, Chen YY, Yang JS, Lin JP, Lien JC, Tsai $\mathrm{CH}$ and Chung JG: Quercetin inhibits migration and invasion of SAS human oral cancer cells through inhibition of NF-KB and matrix metalloproteinase-2/-9 signaling pathways. Anticancer Res 5: 1941-1950, 2015

17 Piantelli M, Maggiano N, Ricci R, Larocca LM, CApelli A, Scambia G, Isola G, Natali PG and Ranelletti FO: Tamoxifen and quercetin interact with type II estrogen binding sites and inhibit the growth of human melanoma cells. J Invest Dermatol 2: 248-253, 1995 .

18 Rosner K, Röpke C, Pless V and Skovgaard GL: Late type apoptosis and apoptosis free lethal effect of quercetin in human melanoma. Biosci Biotechnol Biochem 70: 2169-2177, 2006.

19 Loizzo MR, Said A, Tundis R, Hawas UW, Rashed K, Menichini F, Frega NG and Menichini F: Antioxidant and antiproliferative activity of Diospyros lotus L. Extract and isolated compounds. Plant Foods Hum Nutr 64: 264-270, 2009.
20 Caltagirone S, Rossi C, Poggi A, Ranelletti FO, Natali PG, Brunetti M, Aiello FB and Piantelli M: Flavonoids apigenin and quercetin inhibit melanoma growth and metastatic potential. Int J Cancer 87: 595-600, 2000.

21 Cao H-H, Cheng C-Y, Su T, Fu XQ, Guo H, Li T, Tse AK, Kwan $\mathrm{HY}, \mathrm{Yu} \mathrm{H}$ and $\mathrm{Yu} \mathrm{ZL}$ : Quercetin inhibits $\mathrm{HGF} / \mathrm{c}-$ met signaling and HGF-stimulated melanoma cell migration and invasion. Mol Cancer 14: 103, 2015.

22 Yamauchi K, Mitsunaga $\mathrm{T}$ and Batubara I: Novel quercetin glucosides from Helminthostachys zeylanica root and acceleratory activity of melanin biosynthesis. J Nat Med 67: 369-374, 2012.

23 Yamauchi K, Mitsunaga T and Batubara I: Synthesis of quercetin glycosides and their melanogenesis stimulatory activity in B16 melanoma cells. Bioorg Med Chem 22: 937-944, 2014.

24 Yamauchi K, Mitsunaga T, Inagaki M and Suzuki T: Synthesized quercetin derivatives stimulate melanogenesis in B16 melanoma cells by influencing the expression of melanin biosynthesis proteins MITF and p38 MAPK. Bioorg Med Chem 22: 33313340,2014

25 Ashcroft G, Horan M and Ferguson M: The effects of ageing on cutaneous wound healing in mammals. J Anat 187: 1-26, 1995.

26 Guyton KZ: Age-related decline in Mitogen-activated protein Kinase activity in Epidermal growth factor-stimulated rat Hepatocytes. J Biol Chem 271: 3604-3607, 1996.

27 Reenstra WR, Yaar M and Gilchrest BA: Aging affects Epidermal growth factor receptor phosphorylation and traffic kinetics. Exp Cell Res 227: 252-255, 1996.

28 Shiraha H: Aging Fibroblasts present reduced epidermal growth factor (EGF) responsiveness due to preferential loss of EGF receptors. J Biol Chem 275: 19343-19351, 2000.

Received January 9, 2017

Revised March 3, 2017

Accepted March 7, 2017 